\title{
Psicologia e gestores escolares: mediações estéticas e semióticas promovendo ações coletivas
}

\author{
Psychology and School administrators: Esthetic and \\ semiotic mediations to promote collective actions
}

\author{
Lilian Aparecida Cruz DUGNANI ${ }^{1}$ \\ Vera Lucia Trevisan de SOUZA'
}

\begin{abstract}
Resumo
O presente artigo tem por objetivo apresentar parte de uma pesquisa de doutorado que investigou o potencial das açães do psicólogo escolar na promoção de mudança das práticas de gestão. Adotam-se os pressupostos teórico-metodológicos da Psicologia Histórico-cultural, sobretudo os de Vygotsky. As informações foram construídas a partir de sínteses derivadas da transcrição de gravações em áudio de encontros semanais, com duração média de duas horas, realizados ao longo de quatro anos. Participaram deste estudo um diretor, um vice-diretor e dois orientadores pedagógicos de uma escola pública municipal localizada em uma cidade do interior de São Paulo. Nesses espaços diversas expressões artísticas foram utilizadas como estratégias deflagradoras de reflexão e ampliação da consciência dos gestores. Resultados revelam que é preciso um investimento permanente do psicólogo escolar em espaços que favoreçam a ressignificação, a atribuição de sentidos e a construção de motivos coletivos para que as mudanças nos modos de gerir a escola ocorram.
\end{abstract}

Palavras-chave: Gestores escolares; Psicologia escolar; Psicologia histórico-cultural; Volição.

\begin{abstract}
This article is part of a Doctoral dissertation that investigated the potential of actions carried out by a school psychologist to bring about changes and improve management practices. This study was based on theoretical and methodological assumptions of cultural-historical Psychology, especially the insights of Vygotsky. Data were collected at a municipal public school, located in an inland city in the state of São Paulo, through transcriptions of audio recordings of two-hour weekly meetings over a period of four years. The meetings were held with the school principal, the assistant principal, and two school counselors, participants of this study. During these meetings, artistic expressions were used to encourage reflections and increase administrative staff's awareness. The results obtained indicated that school psychologists should use effective approaches to promote resignification, attribute meanings, and build collective motives to improve school management.
\end{abstract}

Keywords: School manager; School psychology; Historic-cultural psychology; Volition.

\footnotetext{
D.

1 Pontifícia Universidade Católica de Campinas, Centro de Ciências da Vida, Programa de Pós-Graduação em Psicologia. Av. Jonh Boyd Dunlop, s/n., Prédio Administrativo, Jd. Ipaussurama, 13059-900, Campinas, SP, Brasil. Correspondência para/Correspondence to: V.L.T. SOUZA. E-mail: <vtrevisan@puc-campinas.edu.br>.

Apoio: Conselho Nacional de Desenvolvimento Científico e Tecnológico.
} 
O presente artigo tem por objetivo apresentar parte de uma pesquisa de doutoramento que investigou o potencial das ações do psicólogo escolar na promoção de mudança das práticas de gestão na escola. Esse investimento se justifica por acreditarmos que estes profissionais são os principais mediadores dos processos pedagógicos e educativos que se empreendem na escola. É função da gestão, representada pela direção e pela coordenação ou orientação pedagógica, promover condições para a melhoria da qualidade de ensino e formação oferecida aos alunos (Dugnani \& Souza, 2011; Paro, 2015; Placco, Almeida, \& Souza, 2011).

O grupo de pesquisa Processos de Constituição dos Sujeitos em Práticas Educativas (PROSPED) tem investido em ações junto às escolas caracterizadas por pesquisa-intervenção entendida, a um só tempo, como forma de produzir conhecimentos acerca dos fenômenos investigados e meios/procedimentos para acessá-los. Vygotsky (1932/2001), autor cujas acepções sustentam as investigações e atuações deste estudo em contextos educativos, defende que o método é concomitantemente caminho e produto da investigação. Acrescenta-se, ainda, que a pesquisa-intervenção aqui realizada é, simultaneamente, produção de conhecimento sobre o fenômeno, produção de método sobre o acesso ao objeto investigado e formação profissional dos psicólogos para a atuação no contexto escolar.

Nesse sentido, é possível afirmar que a arte tem se constituído como materialidade mediadora na produção do conhecimento, no acesso à informação e nas propostas de ações de intervenção. É materialidade, no que diz respeito às produções artísticas, símbolos da cultura, e mediadora, pois, por meio de seu uso pode-se atingir a subjetividade dos sujeitos, favorecendo sua expressão e promovendo o desenvolvimento da consciência de si e do outro (Petroni \& Souza, 2014; Souza, Petroni, \& Dugnani, 2011).

As materialidades mediadoras têm se revelado uma estratégia deflagradora de movimentos de reflexão e ampliação da consciência, caracterizando o que pode ser chamado de dupla função: o seu caráter estético, no que concerne à forma, porta uma dimensão semântica, no que se refere ao conteúdo, sendo esta, promotora de novas significações. Estética e semiótica constituem a unidade da mediação, ou seja, a arte é utilizada como mediação para provocar, intencionalmente, a ampliação da consciência dos sujeitos, movimento que pode promover a transformação das relações no contexto escolar.

A dimensão semiótica reporta às esferas cognitivas e racionais do homem, trata-se da "capacidade de saber fazer", estando, portanto, para além do simples conhecimento. Já a estética refere-se à dimensão do sensível, do sentir o que se faz, superando, portanto, a capacidade de perceber (Pino, 2010). Acrescenta-se, ainda, a dimensão volitiva, gerada pelo afetivo, mas que incorpora as significações e dispara um movimento o qual possibilita o desenvolvimento de uma ação conscientemente direcionada pelo sentir e pelo pensar. Essas três dimensões, que se articulam de modo dialético e indissociável, constituem o agir humano.

As acepções e constatações resultantes das práticas de pesquisa e intervenção aqui relatadas pareceram promissoras como direcionadoras das ações do psicólogo na gestão escolar. Importa declarar que o interesse desta pesquisa não está fundamentado na arte como campo de conhecimento, mas na Psicologia da arte. Esta auxilia na compreensão do potencial do uso das produções artísticas como favorecedoras das mediações estéticas e semióticas que podem promover movimentos de reflexão (Petroni \& Souza, 2014; Souza et al., 2011).

A contribuiçãa da arte para mediar os processos reflexivos na escola revelou ser de fundamental importância no caso dos gestores. Estes são, tradicionalmente, representados como apartados da prática pedagógica, envolvidos somente com a administração da escola e, no caso dos diretores, os quais ocupam a instância máxima de poder, como indivíduos com dificuldade em estabelecer relações mais abertas e receptivas, notadamente com os professores (Paro, 2015).

A disponibilidade de diretores e coordenadores pedagógicos para se envolver em atividades de reflexão também tem sido bastante questionada pela literatura. O que se afirma, é que esse espaço de formação de gestores não ocorre na escola, mas 
em instâncias superiores de administração da educação, como núcleos pedagógicos, diretorias de ensino e a própria secretaria da educação (Gomes, 2013; Paro, 2011; Vieira, 2011).

As questões que emergem dessa condição são: se a gestão é a instância mediadora dos processos pedagógicos na escola com vistas à melhor qualificação do ensino e aprendizagem, e se o alvo dessa mediação é a docência, constituída pelo coletivo de professores, como trabalhar o coletivo sem desenvolver práticas gestoras colaborativas? Como obter resultados nas ações gestoras se elas não estiverem em sintonia dentro da própria equipe? Como avançar nos processos de gestão sem investir coletivamente na promoção da vontade de mudar as próprias ações para promover vontade de mudança coletiva nos professores?

O investimento na utilização da arte como estratégia de intervenção do psicólogo na escola se sustenta na potencialidade desta materialidade mediadora que, ao assumir a condição de instrumento psicológico, afeta os sujeitos, despertando suas emoções e possibilitando que vivenciem as relações com os outros e consigo próprios de um modo novo. Os afetos, que segundo Vygotsky estão na base de toda ação ou pensamento, põem a consciência em movimento, consciência entendida como relação entre as funções psicológicas que produzem novos significados e sentidos, equivalendo, assim, ao próprio sistema psicológico (Clot, 2014; Petroni \& Souza, 2014; Vygotsky, 1931/1995b). No caso da escola, sobretudo dos gestores, as vivências estéticas promovem a quebra da rotina de um cotidiano repleto de conflitos, criando um espaço menos tensionado para pensar as questões que aportam na gestão.

É fundamental, no entanto, que o psicólogo escolar empreenda uma busca intencional e cuidadosa de produções artísticas cuja apreciação resulte

na promoção da reflexão pela confrontação dos elementos das obras - síntese do humano e, portanto, com significados comuns para quem as aprecia, e os sentidos que esses elementos despertam em cada uma das pessoas, os quais se relacionam com suas experiências e suas histórias singulares (Souza, 2015, p.118).
Reflexão que é condição para a construção de um coletivo que se constitua como força motriz e apoio ao investimento persistente na superação das tensões e contradições que caracterizam os processos de mudança (Souza et al., 2011).

\section{Método}

A pesquisa ora relatada teve como objeto de estudo os processos de mudança vivenciados por um grupo de gestores escolares, tomando como fundamento epistemológico o materialismo histórico e dialético. Adotar essa perspectiva demandou considerar o fenômeno em sua totalidade, implicando na análise do movimento parte-todo que produz as sínteses representadas nos modos de ser e agir da gestão, considerando, também, as relações internas e externas à escola promovidas ou vivenciadas pelos gestores.

Entende-se que esse modo de analisar está baseado em Vygotsky (1927/1991), quando afirma que, para isso, a tarefa fundamental é "... destacar do conjunto psicológico integral determinados traços e momentos que conservam a primazia do todo" (p.99). Sendo assim, foi essencial, para esta pesquisa, conhecer o sujeito em movimento nas interações que estabelece em seu contexto, investigando suas condicionantes, visto serem elas que promovem a emergência do sujeito da maneira como se manifesta (Souza \& Andrada, 2013). São esses os pressupostos que embasam o olhar dos pesquisadores envolvidos neste estudo na inserção no campo de pesquisa e na análise das informações acessadas, visando aproximá-los do todo complexo que envolve o desenvolvimento e a sustentação da vontade consciente nos gestores, constituintes de sua ação no contexto escolar.

\section{Participantes}

Este estudo contou com quatro participantes: um diretor - para o qual adotou-se o nome fictício de Adoniran -, um vice-diretor - a quem deu-se o nome de Manoel -, e dois orientadores pedagógicos - referidos aqui como Leonardo e Camille. 
O locus do estudo foi uma escola pública municipal em uma cidade do interior de São Paulo.

Adoniran, formado em História e Filosofia, era diretor da unidade há nove anos. Manoel, graduado em Pedagogia e Jornalismo, atuava como vice-diretor na escola há três anos. Leonardo, formado em Pedagogia e especialista em Educação Especial, ocupava a orientação pedagógica da unidade de ensino investigada há oito anos. Camille, graduada em Pedagogia e Letras, atuava como orientadora pedagógica na escola há dois anos. Todos tinham experiência na docência por período que variava entre seis e 15 anos. O critério para inclusão dos participantes no estudo foi: exercer o cargo de gestão na escola investigada.

\section{Procedimentos}

Após a concordância dos gestores em participar do estudo foram definidos, junto à psicóloga, o dia da semana, o horário e o tempo de duração dos encontros. Também foram colhidas as assinaturas do Termo de Consentimento Livre e Esclarecido, no qual declarava-se o objetivo da pesquisa e a necessidade de gravação dos encontros.

As informações aqui colocadas foram construídas a partir de sínteses derivadas da transcrição de gravações em áudio de 128 encontros com frequência semanal e duração média de duas horas cada, realizados entre os anos de 2010 e 2013. Estes se caracterizavam como espaços de apreciação e produção artística seguidas de discussão e reflexão do grupo. Após cada encontro, a pesquisadora produzia uma síntese a partir das gravações, acrescentando observações e os sentidos configurados pelos gestores nas discussões segundo sua percepção.

No início do encontro seguinte a síntese era lida com o grupo. Ao final da leitura, um novo diálogo era proposto abordando o seu conteúdo e os sentidos apresentados pela pesquisadora. Nesse momento, uma nova configuração de sentidos se constituía, revelando a síntese como um importante instrumento de mediação semiótica das vivências dos encontros.

A partir dessa leitura, procedeu-se a análise das informações, utilizando-se como norteador a identificação de expressões recorrentes nas falas dos sujeitos que indicavam movimentos de mudança. Das leituras recorrentes foram eleitas 25 sínteses que apresentavam expressões com significação reveladora dos processos de mudança dos gestores. Estas foram denominadas de "expressões com significação de indicadores de escolha" e foram tomadas como unidade de análise das informações acessadas em consonância com o pressuposto teórico-metodológico que ancora esta investigação (Vygotsky, 1931/1995a).

Todo o processo culminou na construção de dois grandes eixos de análise: 1) Enfrentando conflitos $x$ desviando o olhar, e 2) As mediações estéticas e semióticas promovendo a vontade coletiva. Para o propósito deste artigo, será apresentado apenas o segundo eixo, por entender a mediação estética e semiótica como estratégia potente na promoção do desenvolvimento da vontade coletiva.

Conforme preconiza a Resolução n 466/12 do Conselho Nacional de Saúde (São Paulo, 2012) e a Resolução n 016/00 do Conselho Federal de Psicologia (2000), o projeto de pesquisa foi submetido ao Comitê de Ética e aprovado com Parecer $n^{\circ} 460.388$ antes de nossa inserção no campo. Esta pesquisa pode ser considerada de risco mínimo, visto não terem sido utilizados procedimentos que colocaram os sujeitos em situações adversas ou com riscos maiores aos enfrentados em seu cotidiano.

\section{Resultados e Discussão}

\section{Mediações estéticas e semióticas promovendo a vontade coletiva}

\section{O incômodo como mobilizador da vontade de mudar}

Imediatamente após a leitura da síntese, Manoel começa a contar o que havia ocorrido na reunião das professoras na semana anterior, quando foi apresentar-lhes um novo procedimento requerido pela secretaria de educação. Segundo ele, elas [as 
professoras] tiveram o mesmo movimento de sempre, só ouvindo o que queriam ouvir, reclamando do que teriam que fazer, pois não viam vantagens na mudança proposta, e disseram, ainda, que os registros que estavam sendo solicitados poderiam não corresponder ao que de fato acontecia. ... Manoel relata que após diversas tentativas de argumentar com elas, acabou se cansando de tentar fazê-las entender e se despediu, dizendo que já havia passado o recado necessário, ao que as professoras responderam que haviam entendido o que ele queria dizer. Mas em sua opinião, elas já haviam entendido há muito tempo, mas queriam tumultuar (Trecho da síntese que relata o início do encontro do dia 3 de maio de 2010).

Leonardo apontou a dificuldade de as professoras se implicarem com as propostas da gestão, preferindo esperar que os gestores ajam em seu lugar, principalmente em relação à aplicação de ações punitivas [em relação aos alunos], e que, ao serem questionadas se é isso que querem são sempre evasivas (Trecho da síntese de 30 de agosto de 2010).

Parece que a leitura das sínteses dos encontros de 3 de maio e de 30 de agosto de 2010, sobre o que acontecera uma semana antes de cada um deles, colocou em movimento o incômodo da gestão com as constantes resistências dos docentes em relação a seus encaminhamentos. Em ambos os dias, as discussões giraram em torno das dificuldades dos gestores em lidar com as professoras. É como se a leitura tivesse favorecido a confrontação das ideias dos gestores com as do grupo de professores e dos primeiros com a pesquisadora, produzindo novos significados e sentidos gerados pelas contradições resultantes dessa confrontação. É nesse sentido que se afirma ser a síntese uma materialidade mediadora de significações, assumindo a dimensão semiótica da mediação.

Manoel é bastante calmo, fala baixo, pausadamente. Reflete muito antes de tomar uma decisão. A situação narrada por ele representa um momento de perda de controle, onde se fecha ao diálogo e sai da sala. Parece que a emoção, no caso a raiva, assume primazia na orientação da ação de Manoel, levando-o a se fechar. Já Leonardo é mais agitado, ansioso e impaciente, e apresentava dificuldade em se posicionar como gestor em relação aos professores e cobrá-los quanto às suas responsabilidades. Em geral, colocava-se do lado dos docentes e, no caso registrado na síntese, mostrou-se magoado com a evasiva dos mesmos, pois não retribuíram sua parceria e cobraram a punição dos alunos.

Segundo Placco (2002), as exposições afetivas entram "em embate com os pensamentos, modos de interpretação, reações, motivos e outro" (p.10). E é essa dissonância que parece ter ecoado no vice-diretor e no orientador como um incômodo pelo modo como conduziram a relação. Incômodo que indica a mobilização da vontade para mudar a forma de se relacionar com os professores.

No entanto, a síntese, como instrumento de atuação do psicólogo, só se configurará como promotora de mediações semióticas se seu conteúdo tiver sentido para os participantes do encontro. Os sentidos, por sua vez, são produzidos pela mediação estética. A síntese, então, por se configurar como produtora de significações, possibilita ao sujeito saber o que sente e o porquê age daquele modo a partir desses sentimentos, em outras palavras, possibilita atribuir significados e sentidos aos motivos das ações dos outros e às suas próprias.

E é isso que os fazem narrar a situação no momento do encontro. É quando podem viver a experiência de outro modo, não mais imediato, mas mediado, onde a emoção já não assume a prevalência. Ao narrarem suas experiências, Manoel e Leonardo passam a atribuir-lhes novos significados e, ao refletirem, se colocam como sujeitos da relação. Nesse movimento, ao tentar justificar suas ações por meio da resistência das professoras, revelam, para si próprios, uma contradição: embora a intenção fosse a de fazê-las entender a proposta, ambos deixaram de investir, cada um a sua maneira, na instauração do diálogo que possibilitaria enfrentar o conflito. No caso de Manoel, é esse movimento que o leva a produzir nova significação para o ocor- 
rido: a constante resistência das professoras acaba por se constituir como um dos motivos para aumento do cansaço, minando sua paciência, alimentando o seu desânimo e fazendo com que, assim, ele se fechasse ao diálogo.

Segundo Vygotsky (1931/1995b), a memória é uma função do pensamento que auxilia a relação entre a organização, a seleção e a generalização dos conhecimentos, das experiências e das vivências passadas, vinculando-as com as do presente e com o que se almeja para o futuro. É essa relação que possibilita modos mais abstratos de narrar o mundo e a si mesmo e, consequentemente, de agir nele.

A pesquisadora [se referindo ao uso do tempo na escola] dá como exemplo o dia em que as meninas apareceram na porta e todos pararam a reunião para atendê-las. Diz que isto entra como urgência, pois todos pararam o que estavam fazendo para resolver, no mesmo momento, a questão. Leonardo diz que isto não é urgência. Manoel concorda, mas diz que se permitiram parar para resolver. Leonardo pergunta o que se vai fazer, se vai deixar a menina falando sozinha. A pesquisadora diz que a ideia é justamente pensar o que se pode fazer com estas questões. Leonardo diz que este tipo de urgência sempre ocorre na escola, que ele muitas vezes precisou socorrer os alunos. $E$ indaga: "se está sangrando o que se há de fazer?". A pesquisadora pergunta se o caso da dor de cabeça [a equipe gestora mencionou que havia um excesso de alunos reclamando de dor de cabeça e pedindo para ligar para mãe para poder ir embora para casa, disseram que isso tomava parte considerável do tempo de trabalho deles] entra na mesma urgência. Leonardo diz que lógico que não. A pesquisadora diz então que parece que as duas situações estão sendo tratadas da mesma forma. Leonardo concorda que é diferente. Diz que o último caso é sim uma urgência, que no caso da dor de cabeça, o aluno diz estar com dor de cabeça. E aí a gestão tem que ligar para a mãe para saber se ele pode ir embora. cabeça é real, que muitas vezes é uma desculpa para se ir embora da escola. Manoel diz que a escola tem que ligar para mãe e informá-la, não Ihe cabendo verificar a veracidade das informações. Leonardo concorda... . Manoel diz que a localização da sala da gestão favorece que todos passem primeiro por lá (Trecho da transcrição de 2 de outubro de 2012).

O que se observa no excerto acima são os movimentos de tensão dos gestores, resultantes da discussão do conteúdo do texto de Placco (2003), intitulado "O coordenador pedagógico no confronto com o cotidiano da escola", em que afirma a importância das pausas na rotina escolar. Ao refletirem sobre os apontamentos da autora, os gestores se veem diante do drama que caracterizava a maior parte de sua rotina de trabalho na gestão: atender às urgências versus criar e manter espaços para que as atividades planejadas ocorressem. O drama se constitui, neste caso, pela vivência da contradição expressa ao se priorizar o investimento em ações que só reproduzem um modo já apropriado de funcionar da escola: atender às urgências, deixando passar as oportunidades de produzir mudanças genuínas, por meio da criação de pausas que poderiam favorecer a reflexão. E é esse movimento que parece produzir a inquietação que leva os gestores a buscarem alternativas para superá-la.

Retomamos a confecção do plano de gestão [desde o início do segundo semestre de 2012 os gestores estavam construindo um plano de gestão junto com a psicóloga]. Como ponto inicial, escolhemos tratar do problema dos telefonemas para a casa de alunos por conta de dores de cabeça e outros motivos. Camille havia dito que estes eventos acabavam tomando muito do seu tempo, e Leonardo concordara, dizendo que não sobrava muito tempo para se fazer o que era importante. A princípio, os gestores diziam que seria muito dificil mexer naquela dinâmica, pois escola funcionava assim há muito tempo. Manoel discordava - achava que dava para mudar, se a secretaria fechasse ao público no período da tarde, ficando a secretária à disposição das demandas 
internas. Camille discordava dessa proposta, pois achava que as mães reclamariam nas instâncias superiores que mandariam reabri-la. Leonardo concordava com Camille, lembrando que os alunos do Educação Jovens Adultos procuravam a secretaria a tarde. $A$ pesquisadora pergunta se a escola deveria ceder o tempo todo à pressão das mães, e se não era essa a saída, qual seria então, pois Camille e Leonardo não estavam conseguindo tempo para fazer os seus trabalhos, e estavam muito incomodados com isso. A segunda solução seria mexer no horário das secretárias. Todos concordam que não seria uma tarefa fácil. Leonardo diz que não pode ser feito. Manoel diz que pode, pois, o funcionário tem que atender o horário da escola e não a escola atender o horário do funcionário. Todos concordam que com este horário Camille conseguiria abrir mais espaços para realizar o seu trabalho no período da tarde. Manoel pergunta então quem conversaria com elas. A pesquisadora pergunta a quem cabe. Todos afirmam que seria o diretor, mas que esta é uma situação bastante delicada (Trecho da síntese de 16 de outubro de 2012).

Ao mudar radicalmente a direção do que estava sendo dito até então, a saber, explicações do porquê as pausas e os tempos não eram respeitados na escola, Manoel possibilita que o drama seja superado. O desenvolvimento do sistema psicológico promove a escolha voluntária da direção da atenção, do pensamento, da memória, da emoção e da percepção. Ao considerar que a contradição constitui todos os fenômenos humanos, pode-se pensar que as falas dos gestores expressando as dificuldades que encontram para exercer suas atividades, impedidoras de mudanças na gestão da escola, contêm, dialeticamente, a possibilidade de superação dessas mesmas dificuldades.

E é esse movimento que é revelado quando Manoel inquieta-se com as justificativas apresentadas por Camille e Leonardo para a impossibilidade de se alterar a rotina de funcionamento da escola, mesmo sabendo que esta impacta negativamente na qualidade do trabalho da gestão. Percebe-se que o vice-diretor passa a direcionar seus esforços para a superação dessa condição, visto que, ao invés de endossar as falas dos colegas, posiciona-se de modo crítico, perguntando, argumentando e, algumas vezes, refutando as explicações dadas para a manutenção do instituído em um movimento dialético de lembrar o que é e imaginar o que poderá ser.

Acredita-se que a ação só pode ser transformada em dois tempos, no passado, quando é interpretada e, no futuro, quando é planejada. Isso porque, como afirma Vygotsky (1931/1995a), não há luta de motivos no momento da execução da ação, considerando que nessa etapa a decisão já foi tomada, restando apenas efetivá-la. No caso da conversa de Manoel com as professoras, por exemplo, quando sai e as deixa com seus questionamentos, o conflito já foi resolvido pela decisão de não continuar naquele embate.

Ao considerar os gestores como articuladores das relações entre os diversos atores que compõem o espaço escolar, e que essas articulações são permeadas por paradoxos, tensões e contradições, como afirmam Placco et al. (2011), pode-se depreender a importância de espaços que lhes possibilitem recordar suas experiências, significar o que vivem e refletir sobre novas possibilidades de ação como forma de vivê-las de outro modo. Esse movimento, ainda que tímido, é essencial à promoção de mudanças na escola, por possibilitar a ampliação da compreensão dos gestores das idas e vindas, avanços e retrocessos a que está submetida a superação de uma determinada condição.

\section{Olhar de novo para ver o novo: construindo motivos para mudança}

Esse trabalho de vocês é legal. E por que ele é legal? Primeiro, a gente está acrescentando, na nossa agenda diária de trabalho, uma vez na semana, a conversa sobre as coisas que nem sempre, ou a maior parte do tempo, não são da escola... . É lógico que vocês procuram sempre temas relacionados com alguma coisa de dentro da escola, mas, esse espaço que a gente 
conseguiu..., ele está dando um certo resultado porque, pelo menos, eu não começo a semana como eu estava sempre começando. Adoniran diz que antes, a única coisa diferente que a gestão sabia fazer naquele espaço era comprar salgadinho e comer. E ressalta: o que vocês fazem [o trabalho com arte], fortalece até a nossa própria relação aqui. Porque é o momento em que a gente se expõe um pouco mais e de uma outra forma, você acaba conhecendo um pouco mais do outro (Trecho da fala de Adoniran mobilizada pela apreciação da síntese no início de um encontro em 21 de junho de 2010, seis meses após o início da intervenção).

Eu acho que essas outras possibilidades que, às vezes, vocês falavam para a gente refletir que eu acho que são legais. Às vezes, é ouvir a música, discutir, é desenvolver o trabalho com a massinha. Eu acho que são coisas que a gente não se permite, a gente no dia a dia não tinha... . (Fala de Leonardo quando questionado sobre o trabalho desenvolvido, encontro de avaliação de 18 de junho de 2011).

Adoniran e Leonardo destacam a importância dos nossos encontros por entenderem que propiciam a vivência do cotidiano de outro modo, pois por meio de suas atividades os vínculos são fortalecidos na gestão. Ressaltam, ainda, a possibilidade de se mostrar e conhecer um ao outro de outro jeito.

Assim, as intervenções com expressões artísticas acabaram por se constituir como um motivo auxiliar que coloca a reflexão dos gestores em movimento. Esse processo favorece a elaboração de sínteses por cada um dos gestores e pelo grupo como um todo, ressignificando as contradições e transformando-as em potência de ação, possível devido à emergência da confiança e da segurança no e do grupo. Eéa esse movimento que Leonardo e Adoniran se reportam, ao afirmarem que aqueles espaços possibilitavam conhecer melhor um ao outro.

Manoel diz que do ponto de vista pessoal o

254 tem um ganho, um espaço para reflexão, onde podem conversar e que isso tem reflexo no seu trabalho como um todo, que independentemente de onde vamos chegar, os ganhos sempre vão acontecer. Leonardo diz que é um momento que se pode pensar diferente e que isso é que é importante (Trecho da transcrição do dia 20 de agosto de 2013, neste encontro reavaliava-se o trabalho).

Em minha opinião, o que fazemos aqui com vocês ainda faz sentido, exatamente porque é uma quebra. Pelo menos, em uma quarta-feira, existe uma quebra de rotina. Vocês ainda não são rotina, é uma quebra da rotina. Quando vocês chegam aqui, a gente nem imagina para onde que vai a conversa. É diferente de dizer: "Olha, vamos parar...". Como a gente tem que parar de segunda-feira para conversar. Conversar por quê? Vai escrever o quê aqui se a gente está junto no dia a dia? Agora não, obrigatoriamente, a gente está parado. Você entende? Nós estamos deixando de fazer alguma coisa para a escola. É ruim? Não. É uma quebra só (Fala de Adoniran quando questionado sobre o trabalho desenvolvido encontro de avaliação de 16 junho de 2012).

Foi pedido aos gestores, depois da leitura do poema Autorretrato de Mario Quintana, que fizessem o seu autorretrato e, para tal, foram fornecidas folhas de sulfite e riscadores diversos. Após todos terminarem, pedimos que falassem um pouco sobre os seus desenhos. Adoniran explicou seu desenho [uma casa no meio do mato] dizendo que há uma realidade que ele vive, mas sempre há algo fora, que ele acha que é bonito, que o faz continuar, que o faz buscar novas coisas, que o faz acreditar. É nesse algo a mais que sempre pensa (Trecho da síntese de 3 de maio de 2010).

Eu volto a dizer, é importante ter esse espaço que a gente fez dele obrigatório, na semana, para discutir alguma coisa diferente, para falar uma coisa diferente, para conversar 
com vocês, que estão envolvidas com a escola, mas não pertencem à escola. Então, se torna uma coisa boa, porque muitas vezes até o desabafo da gente com uma coisa e com outra sempre acontece. Mas, é bom, porque, eu acredito que muitas coisas acontecem comigo e devem acontecer com os outros também. Tem algum assunto que se puxa aqui dentro e depois nos leva a ter a reflexão de uma coisa ou de outra durante a semana, nem que for para discordar. Então, eu vejo por aí e eu nunca vi assim... (Fala de Adoniran na avaliação semestral do trabalho transcrição da avaliação de 18 de junho de 2011).

Como já havíamos afirmado anteriormente, na escola tudo parece ser emergência e é Adoniran quem nos indica o porquê de a arte conter um potencial sensibilizador, o qual pode promover uma transformação nas relações: trata-se das quebras dos ritmos que se imprimem no contexto escolar. A apreciação e fruição de uma expressão artística demandam contemplação e reflexão, convidam o sujeito a colocar o foco naquilo que, em geral, passa despercebido. Pode-se depreender dessa afirmação que a arte é uma via potente na promoção do estranhamento do cotidiano, o qual é disparador do processo de mudança.

As falas de Adoniran parecem se referir ao valor das interações na construção e manutenção dos motivos que sustentam a sua crença na importância do que faz; refere-se, ainda, ao tempo ao qual esse processo está submetido. O diretor parece compreender que é o investimento nesses momentos que favorecerá uma mudança e que este é um movimento lento e contínuo.

Esse pequeno passo talvez seja um dos mais importantes para a promoção de mudanças estáveis nos modos de relação na escola, visto evidenciar a relevância do investimento nos processos de significação, ressignificação e atribuição de sentidos aos motivos que sustentam as ações. Podem favorecer, também, a construção de motivos que sustentem novas ações, visto convidar o sujeito continuamente a "olhar de novo para ver o novo" como um processo de tomada de consciência.
É fato que tomar consciência da importância das interações na constituição dos motivos que levam os sujeitos a agir é uma parte importante do processo de mudança, mas não o encerra. Isso porque, como afirma Vygotsky (1932/2001), para que se efetive uma transformação na conduta muitas mudanças internas precisam ocorrer, o que significa dizer que é necessário um investimento permanente na criação de situações que possibilitem aos sujeitos vivenciar os movimentos de avanços e retrocessos que caracterizam esse processo.

A ação coletiva é construída a partir da atribuição de significados e sentidos que ocorrem a um só tempo por cada membro da equipe e pelo grupo, em um movimento de idas e vindas, que permite ao sujeito se expressar, discordar, se distanciar e se aproximarem. Ou seja, ela se caracteriza como drama a ser vivido, enfrentado e superado em um movimento dialético permanente.

\section{A reciprocidade das relações promovendo a vontade coletiva}

O que é importante na sintese é essa observação que vocês trazem junto, pela oportunidade de ouvir uma, duas vezes, de captar alguma coisa que no calor da discussão aqui passou despercebido. Então, de resgatar isso, trazer para a gente na semana seguinte, eu acho que é importante. Por outro lado, também essa construção, juntos da sintese, de ter que lembrar, isso te compromete. Não é aquela coisa que você está aqui agora falando e depois você esquece... (Trecho da avaliação de 18 de junho de 2011 - Manoel).

Manoel diz que Camille tem uma coisa própria dela, do jeito de ver, que pelo menos ele acha legal. Pode até não concordar, mas é legal. A pesquisadora diz que é isso que faz o grupo, não concordar mas ouvir. $E$ Camille complementa dizendo que, mas se ouve, respeita, argumenta, reflete... (Trecho da avaliação de 18 de junho de 2011 - Manoel). 
No dia a dia a coisa é mais racional, é: "Aquilo que tem que ser feito, o conceito. Como vamos fazer?" Aqui não, aqui é outra construção. Eu acho que isso que é legal, eu acho que essas oportunidades, essas estratégias, eu acho que é isso, elas vão permitindo a gente reconstruir determinados caminhos, determinadas situações, rever (Trecho da transcrição da avaliação de 18 de junho de 2011 - Leonardo).

A constituição da coletividade perpassa pela reciprocidade das relações entre os sujeitos singulares no grupo, de modo que cada um e todos se sintam acolhidos e acolham os objetivos coletivos que os unem. Isso revela que é necessária tanto uma ação do grupo em relação ao sujeito quanto deste em relação à equipe. $E$, ao que parece, é a essa aproximação e construção de objetivos comuns, por meio do compartilhamento das possibilidades e limitações, concordâncias e discordâncias, que se referem os gestores nas falas acima. Embora Manoel mencione a importância das sínteses como instrumento que os auxilia na responsabilização e no compromisso com os projetos que eles mesmos propõem, é possível afirmar que traz, também, as afecções que foram produzidas pela arte, visto que as mediações estéticas e semióticas constituem uma unidade indissociável na promoção da mudança.

\section{O diálogo sustentando a mobilização da vontade coletiva}

Assim, é a transformação, a qual vai ocorrendo nas relações que os gestores estabelecem com o meio, com os outros e consigo próprios, que vai possibilitando que os discursos sejam transformados em diálogos, característica fundamental para a instituição do coletivo como modo de funcionar da gestão. Compreende-se por discurso a fala construída social e historicamente com o intuito de reproduzir e propagar uma ideia, não sofrendo abalos com questionamentos, tampouco com discordâncias. O discurso usado como forma de comunicação mediadora nas interações entre os sujeitos acaba por produzir uma hegemonia paralisadora zido pelas pessoas, o que resulta em sentimento de impotência paralisadora (Brandão, 2011).

Os diálogos acabam por favorecer a mediação pela possibilidade de atribuição de sentidos, visto que ao discutir e perceber que todos os membros da equipe deixam de lado o que é essencial para o bom desenvolvimento de seu trabalho em detrimento do atendimento de "urgências", novos objetivos são traçados e passam a se envolver com o desenvolvimento de um plano de gestão, a partir do que entendem como prioritário em suas ações. Essa aproximação de sentidos parece favorecer o compartilhamento dos motivos que mobilizam a vontade de mudar coletivamente.

\begin{abstract}
A pesquisadora diz que como encerramento gostaria que eles representassem plasticamente o que e como estão se sentindo com este trabalho de plano de gestão. Manoel, após fazer o seu desenho, diz que vê uma luz no fim do túnel. Camille diz que está muito confusa ainda e Leonardo diz que só representou, deixou as emoções fluírem, por isso é difícil falar, mas diz que há algo como sangue e esperança, que ele está esperançoso em relação a este trabalho (Trecho da síntese de 16 de outubro de 2012).
\end{abstract}

Parece que, quando a possibilidade de objetivação de uma transformação começa a circular no grupo, mobilizam-se investimentos em novas ações coletivas, as quais suscitam nos sujeitos o desejo de vivenciar a gestão como colaboradores e não mais como juízes das ações e condutas que emergem na gestão e na escola como um todo. E é essa capacidade de decidir, de colocar em prática e realizar o que foi planejado que possibilita a significação do plano de gestão:

Adoniran diz que em relação ao problema da secretaria decidiu que não se ligará mais para os pais. Pergunta a Manoel se não há como mandar um bilhete para casa dos pais. A pesquisadora ressalta que Manoel havia pensado nesta possibilidade no encontro anterior. Manoel diz que não vê problema em encaminhar um bilhete aos pais com as novas informações. A pesquisadora pergunta a Leonardo e a Camille como irão 
estruturar o tempo. Camille e Leonardo pensam um pouco e dizem que os Trabalhos Docentes Coletivos (TDC) serão realizados no mesmo dia e em horários diferentes o que facilitará que um acompanhe o trabalho do outro e também resolverá o problema do espaço físico, uma vez que podem utilizar a informática. Em relação à informática Camille diz que pensa nos professores que utilizam a sala, que ficarão sem este horário. Manoel diz que estes não são a maioria dos professores, e que os horários podem ser pensados para que eles não fiquem nas primeiras aulas nas quintas-feiras. Após definir-se como seria estruturado o tempo de trabalho dos orientadores pedagógicos a pesquisadora pergunta qual seria o teor das reuniões. Leonardo e Camille concordam que as reuniões individuais com os professores, devam ter como eixo central o assessoramento pedagógico, no sentido de ajudar o professor a pensar em estratégias e auxilio na escolha de materiais que possam ajudá-lo na promoção de um ensino de maior qualidade para os alunos (Trecho da síntese de 23 de outubro de 2012).

O desenvolvimento da vontade se mostra importante no processo de mudança, pois trata-se da reunião das forças necessárias para que se possa fazer o que é preciso ser feito como modo de promover a superação dos desafios. O desenvolvimento da vontade coletiva se torna possível pelo confronto mediado das contradições que emergem em seus contatos com as materialidades mediadoras e que os levam a questionar de que modo se pode ser gestor. Como afirma Vygotsky (1927/1991), para compreender o fenômeno é preciso abarcar as suas contradições como sua parte constituinte; do mesmo modo, para promover os processos de mudança, é preciso colocar em evidência as contradições e paradoxos que estão na base dos modos de agir dos gestores escolares.

Isso porque, segundo Bozhovich (2004), os conflitos que ficam apenas no âmbito interno têm, em sua base, motivos não conscientes, fazendo com que, muitas vezes, embora tendo clareza de seus objetivos, o sujeito aja de modo contrário ao que almeja. Por isso, os movimentos de falar, dialogar, questionar e confrontar mostram-se tão importantes na constituição de novos motivos que sustentariam novas ações.

É possível pensar que os gestores passaram a se assumir como autores de suas ações, pois, ao partilharem a possibilidade, passam a levantar uma série de caminhos, ainda que complexos. Esses espaços mediados e mediatizantes, possibilitam que vivenciem, elaborem e construam sínteses do que é ser gestor na escola em questão. Além disso, ao ressignificar as contradições, estas parecem se transformar em potência de ação, como observado abaixo, quando referem-se à maneira como percebem as transformações na escola ao longo dos quatro anos de trabalho.

Manoel diz que nos quatro anos que está nessa escola percebe um avanço considerável. Primeiro, porque a equipe se completou com a sua chegada e a chegada da Camille. Isso viabilizou um acompanhamento mais de perto. Segundo, porque começaram a planejar as ações. Manoel explica que as articulações são feitas primeiro com a reunião da equipe gestora, que isso é fundamental para afinarem as ações. Mesmo que ele e Adoniran não estejam em TDC nesse momento eles estão falando em nome da equipe, do que foi combinado em reunião, e o que não foi combinado não haverá posicionamento do Leonardo ou da Camille no momento do TDC. Que eles levarão para a reunião para a equipe discutir. Que isso dá um pouco de unidade na equipe, visto que não se tem iniciativas isoladas. Diz que percebem que eles já conseguiram avançar bastante no sentido de fazer com que o planejamento dos professores não seja um calhamaço de papel para cumprir com a formalidade. Que os professores o pegam, reveem o que foi possivel trabalhar, o que não foi possível, o que é preciso replanejar. Os professores começam a perceber, alguns mais e outros menos, que é um instrumento que eles usam para orga- 
nizar o trabalho e não apenas uma formalidade para entregar para a direção (Trecho da transcrição de 21 de maio de 2013).

Adoniran diz que quando se fala em ação, que tem coisas planejadas e que estas em sua maioria são cumpridas, e que fazem parte do Projeto Político Pedagógico (PPP). Assim como os imprevistos que acontecem diariamente também fazem parte do PPP. Adoniran disse, que quando começou a sair para olhar a entrada pensou que os outros iriam ficar muito bravos, e que foi percebendo que as pessoas foram chegando, e ele foi tendo aliados (Trecho da transcrição de 21 de maio de 2013).

Leonardo explica que naquele momento não poderá participar da reunião porque precisa priorizar as fichas descritivas que serão discutidas com os professores na próxima sexta-feira, mas que como ficará na mesma sala que nós estará ouvindo o que estamos discutindo e sente-se participando (Trecho da transcrição de 17 de setembro de 2013).

Como se pode perceber, a priorização das ações planejadas melhorou consideravelmente os modos de relação entre os próprios gestores e os demais membros que constituem a escola, sobretudo os professores e os alunos, resultando na melhoria das práticas escolares. Os gestores, ao se orientarem pelo Projeto Político Pedagógico naquele contexto, fizeram com que a dimensão profissional assumisse primazia na mediação das relações na escola.

\section{Considerações Finais}

As mediações estéticas e semióticas promovidas pelas artes e pelas sínteses possibilitaram aos gestores vivenciarem dois movimentos essenciais para a efetivação de mudanças no modo de exercer a gestão na escola: a migração da emoção e a mobilização da vontade. Importa clarear, no entanto, que ambas são partes necessárias para que se bastam por si só. Isso porque, embora a arte seja uma importante ferramenta de afecção do sujeito, são as mediações que decorrem de seu uso como instrumento que favorecerão o desenvolvimento da vontade coletiva.

Do mesmo modo, é importante destacar que, embora os afetos estejam na base da constituição dos motivos, fazê-los fluir não é o suficiente. É preciso que o sujeito signifique suas emoções como modo de transformá-las em um movimento dialético permanente. No entanto, seria possível afirmar que o coletivo, como modo de funcionar da gestão, está consolidado na escola pesquisada?

Considerando, a partir de Petrovski (1984), que o coletivo se caracteriza pela reunião de pessoas as quais compartilham valores, intenções, motivos e objetivos, pode-se dizer que, por algum tempo, essa equipe se constituiu como uma coletividade, aumentando as possibilidades de promover mudanças efetivas na escola. Contudo, como afirma o mesmo autor, uma vez alcançado essa desenvolvimento, não significa que o grupo se manterá nele.

Assim, o desenvolvimento da coletividade é um processo dinâmico, o qual demanda o investimento permanente na atribuição de significados e sentidos do sujeito para o grupo e do grupo para o sujeito, o que é possível por meio da reflexão. Logo, as alterações das demandas externas também provocam mudanças nos modos de funcionar da equipe, caracterizado por movimentos de avanços e retrocessos.

Para que a mudança possa ocorrer na escola, portanto, é preciso um investimento permanente em espaços que favoreçam a ressignificação, atribuição de sentidos e construção de motivos coletivos. Acredita-se, ainda, que a ação do psicólogo em muito contribui na mediação das relações na e da gestão, promovendo a reflexão rumo à ressignificação do que é e do que pode ser a gestão escolar.

\section{Colaboradores}

Todos os autores contribuíram na concepção e desenho do estudo, análise dos dados e redação final. 


\section{Referências}

Bozhovich, L. I. (2004). Developmental phases of personality formation in childhood (II). Journal of Russian and East European Psychology, 42(4), 55-70.

Brandão, H. H. N. (2011). Les esclaves dans les petites annonces des journeaux brésiliens au dix-neuvième siècle: discours et idéologie. Argumentation et Analyse du Discours, 7, 1-14.

Clot, Y. (2014). Vygotsky: a consciência como relação. Psicologia \& Sociedade, 26(esp. 2), 124-139.

Conselho Federal de Psicologia. (2000). Resolução n 16, de 9 de dezembro de 2000. Dispõe sobre a realização de pesquisa em Psicologia com seres humanos. Recuperado em novembro 1, 2015, de http://www. crpsp.org.br/portal/orientacao/resolucoes_cfp/fr_ cfp_016-00.aspx

Dugnani, L. A. C., \& Souza, V. L. T. (2011). Os sentidos do trabalho para o orientador pedagógico: contribuições da Psicologia Escolar. Psicologia da Educação, 33, 29-47. Recuperado em novembro 18, 2015, de http://pepsic.bvsalud.org/scielo.php?script=sci_ arttext\&pid=S1414-69752011000200003

Gomes, R. M. (2013). Entre o autoritarismo e diálogo: a democracia como processo na gestão escolar (Dissertação de mestrado não-publicada). Universidade Federal de São Carlos.

Paro, V. H. (2011). Progressão continuada, supervisão escolar e avaliação externa: implicações para a qualidade do ensino. Revista Brasileira de Educação, 16(48), 695-716.

Paro, V. H. (2015). Diretor escolar: educador ou gerente? São Paulo: Cortez.

Petroni, A. P., \& Souza, V. L. T. (2014). Psicólogo escolar e equipe gestora: tensões e contradições de uma parceria. Psicologia: Ciência e Profissão, 34(2), 444-459.

Petrovski, A. V. (1984). Personalidad, actividad y colectividad. Buenos Aires: Cartago.

Pino, A. S. (2010). Estética e semiótica: sensibilidade e razão na Grécia Antiga. In A. Pino, L. M. Schlindvein, \& A. A. Neitzel (Orgs.), Cultura, escola e educação criadora (v.1, pp.11-30). Curitiba: CRV.

Placco, V. M. N. S. (2002). Formação e prática do orientador e do educador ( $5^{\mathrm{a}}$ ed). Campinas: Papirus.

Placco, V. M. N. S. (2003). O coordenador pedagógico no confronto com o cotidiano da escola. In V. M. N. S. Placco \& L. R. Almeida (Orgs.), O coordenador pedagógico e o cotidiano da escola (pp.47-60). São Paulo: Loyola.
Placco, V. M., Almeida, L. R., \& Souza, V. T. (2011). O coordenador pedagógico e a formação de professores: intenções, tensões e contradições. Recuperado em novembro 18, 2015, de http://www.fvc.org.br/pdf/ apresentacao-coordenadores-qualitativo.pdf

São Paulo. Secretaria da Administração Penitenciária. (2012). Resolução $n^{\circ}$ 466, de 12 de dezembro de 2012. Dispõe sobre as diretrizes e normas regulamentadoras de pesquisas envolvendo seres humanos. Recuperado em novembro 5, 2015, de http://www. sap.sp.gov.br/download_files/pdf_files/comite_de_ etica_em_pesquisa_SAP/resolucao-466_12-12.pdf

Souza, V. L. T. (2015). Educação, valores e formação de professores: contribuições da Psicologia Escolar. In C. M. Marinho-Araújo (Org.), Psicologia Escolar: novos cenários e contextos de pesquisa, formação e prática (pp.115-130). Campinas: Alínea.

Souza, V. L. T., \& Andrada, P. C. (2013). Contribuições de Vygotsky para a compreensão do psiquismo. Estudos de Psicologia (Campinas), 30(3), 355-365. http://dx. doi.org/10.1590/S0103-166X2013000300005

Souza, V. L. T., Petroni, A. P., \& Dugnani, L. A. C. (2011). A arte como mediação nas pesquisas e intervenção em Psicologia Escolar. In R. S. L. Guzzo \& C. M. Marinho-Araújo (Orgs.), Psicologia escolar: identificando e superando barreiras (v.1, pp.261-285). Campinas: Átomo.

Vieira, A. P. G. F. (2011). Formação dos gestores escolares no contexto das políticas de avaliação da aprendizagem (Dissertação de mestrado não-publicada). Universidade Estadual do Ceará.

Vygotsky, L. S. (1991). El significado historico de la crisis de la Psicologia. In L. S. Vygotsky. Obras escogidas (Tomo I, pp.259-413). Madrid: Visor. (Originalmente publicado en 1927).

Vygotsky, L. S. (1995a). Conclusiones. Futuras vias de investigácion. Desarrollo de la personalidade del niño y de su concepción del mundo. In L. S. Vygotsky. Obras escogidas (Tomo III, $2^{\text {a }}$ ed., pp.327-348). Madrid: Visor. (Originalmente publicado en 1931).

Vygotsky, L. S. (1995b). Desarrollo de las funciones mnémónicas y mnemotécnicas. In L. S. Vygotsky. Obras escogidas (Tomo III, $2^{\text {a }}$ ed., pp.247-264). Madrid: Visor. (Originalmente publicado en 1931).

Vygotsky, L. S. (2001). El problema de la voluntad y su desarrollo em la edad infantil. In L. S. Vygotsky. Obras escogidas (Tomo II, $2^{\mathrm{a}}$ ed., pp. 439-450). Madrid: Visor. (Originalmente publicado en 1932).

Recebido: novembro 30, 2015 Aprovado: dezembro 21, 2015 
